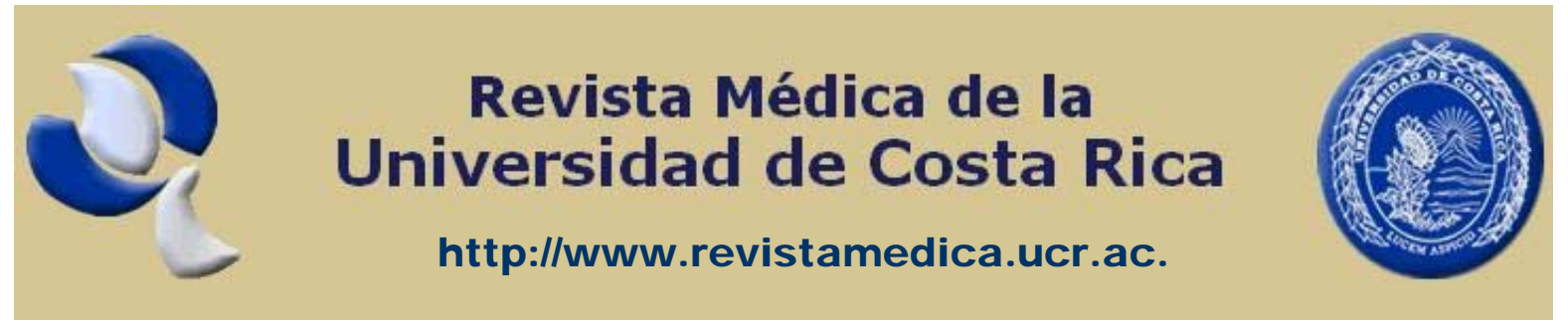

Medicamentos nuevos

\title{
Vareniclina; una ayuda para dejar de fumar.
}

\author{
Ronald González Argüello \\ Departamento de Farmacología \\ Escuela de Medicina de la Universidad de Costa Rica
}

\begin{abstract}
Resumen: La vareniclina es un medicamento aprobado por la FDA en mayo de 2006 para ayudar a las personas que quieren dejar de fumar. La vareniclina es un agonista parcial de los receptores cerebrales nicotínicos $\alpha 4 \beta 2$, asociados a las ansias y síntomas de supresión de los que fuman. Varios estudios clínicos han evaluado la eficacia de la vareniclina en más de 3500 fumadores crónicos. La vareniclina (1m/day) fue comparada con el bupropión (150mg/bid) y con el placebo en dos estudios publicados en la revista de la Asociación Americana de Medicina en julio del 2006. Estos estudios demostraron la eficacia de la vareniclina, sobre todo, durante las doce primeras semanas de tratamiento. La vareniclina es un medicamento efectivo por vía oral para dejar de fumar, pero no es una panacea. Por ahora muchas preguntas permanecen sin responder.
\end{abstract}

Palabras claves: fumado, vareniclina, bupropión, abstinencia

Recibido: Junio 2007. Aceptado: Julio. Publicado: Septiembre 2007.

Abstract: Varenicline was approved by the Food and Drug Administration (FDA) on May 11, 2006 in order to help people who want to quit smoking. Varenicline is a parcial agonist for the $\alpha 4 \beta 2$ nicotine receptors in the brain that are responsible for craving and withdrawal associated with nicotine use. Several clinical trials evaluating varenicline efficacy have been conducted in more than 3500 chronic smokers. Varenicline (1mg/day) was compared with sustained-release bupropion $(150 \mathrm{mg} / \mathrm{bid})$ and placebo in two trials published in July 2006 by the Journal of American Medical Association. These trials demonstrated the efficacy of varenicline, particularly, during the first 12 weeks of

Revista electrónica publicada por la Escuela de Medicina de la Universidad de Costa Rica, 
treatment. Vareniclina is an effective oral agent for smoking cessation, but it is not a panacea. At this time many questions remain without answer.

Keywords: smoking, varenicline, bupropion, abstinence.

\section{Introducción:}

La Vareniclina es un producto de la casa Pfizer, que es comercializado en los Estados Unidos (EU) con el nombre de Chantix®. Este producto fue aprobado para su venta en E U en mayo del 2006 [1]. Su aprobación, por la FDA, tuvo prioridad por los posibles beneficios del medicamento y dado que en EU existes 45 millones de fumadores y al menos 8 millones sufren una enfermedad relacionada al fumado de tabaco [2].

Se supone que la vareniclina al ser un agonista parcial de los receptores nicotínicos $\alpha 4 \beta 2$ estimularía estos receptores y reduciría el síndrome de abstinencia de la nicotina, mientras que si el sujeto fuma, la misma vareniclina limitaría el acceso de la nicotina a sus receptores y por tanto reduciría su efecto, limitando de esta manera la liberación dopaminérgica en la vía mesolímbica, la cual esta implicada en la adicción [3].

\section{Presentación farmacéutica}

Tabletas blancas biconvexas con recubrimiento por película con 0,5mg de vareniclina. En una cara de la tableta dice Pfizer y en la otra $\mathrm{CHX} 0,5$.

Tabletas celestes biconvexas con recubrimiento por película con $1 \mathrm{mg}$ de vareniclina. En una cara de la tableta dice Pfizer y en la otra CHX 1.0.
¿Al reaccionar la vareniclina con receptores nicotínicos, tal y como lo hace la nicotina, puede su uso a largo plazo generar adicción?

Con respecto a esta pregunta el fabricante responde [3]: Que menos de uno de cada mil personas que consumen vareniclina indican sentir euforia al consumir el fármaco. En los estudios no ha habido evidencia de escalamiento de la dosis, lo que habla en contra de una tolerancia. Un 3\% de los pacientes reportan irritabilidad y trastornos del sueño, al suspender el fármaco bruscamente, lo que habla de dependencia física, pero no de adicción. Estudios en animales, parecen indicar que estos igual abusan de la vareniclina como de la nicotina [3]. Habrá que ver estudios de largo plazo para poder identificar adecuadamente esta problemática. Por el momento no existe ninguna restricción de la FDA con respecto a esto.

Las tabletas deben almacenarse entre 15 y 30 grados centígrados.

Paquete de inicio: 11 tabletas de $0,5 \mathrm{mg}$ en un blister y 42 tabletas de $1 \mathrm{mg}$ en tres blister de 14 tabletas cada uno.

Paquete de continuación: 56 tabletas de un miligramo en cuatro blister de 14 tabletas cada uno. 


\section{CHX T.0}

Tomado de: www.prescribingreference.com/images/Products/chantix.gif

\section{Inicio de tratamiento:}

Se recomienda iniciar el tratamiento unos siete días antes del día determinado (para tener concentraciones de estado estacionario) para dejar de fumar.

En lo primeros tres días debe tomar 0,5mg al día, del día 4 al 7 tomar 0,5mg dos veces al día (bid) y luego una tableta de un miligramo bid. Este tipo de esquema reduce la frecuencia de náuseas, su principal efecto adverso. Por esto mismo se recomienda tomar la medicación con alimento y suficiente agua [4].

La duración del tratamiento es de tres meses.

\section{CHANTIX (varenicline) IAABlets}

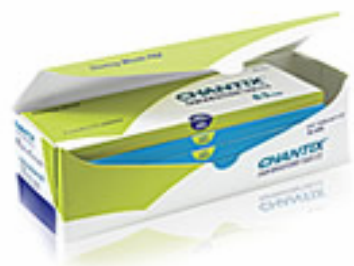

Starting Month PAK

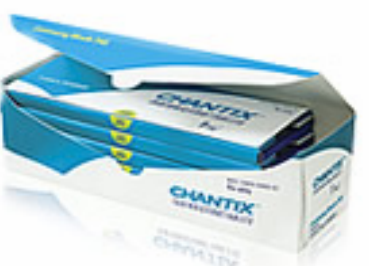

Continuing Month PAK

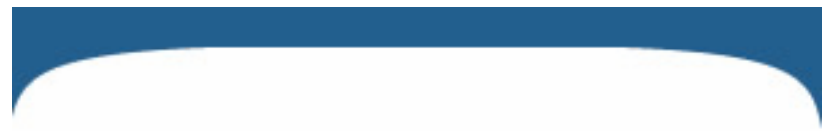

.


No hay que ajustar la dosis en insuficiencia hepática. Para las interacciones se ha valorado el transportador renal de cationes orgánicos, sin que revele interacciones clínicas importantes hasta la fecha [5].

El medicamento se puede eliminar mediante hemodiálisis.

Con aclaramientos de creatinina de más de $30 \mathrm{ml} / \mathrm{min}$ no se altera mayormente la cinética de la vareniclina $y$ no se requiere ajustar la dosis. Con

\section{Discusión:}

De los estudios que aquí se presentan sobre la vareniclina $[7,8,9]$ (ver gráficos 1,2 y 3) es claro que esta es más eficaz que el placebo, y aparentemente, más que el bupropión para dejar de fumar en el corto plazo, tres meses. Si se quiere mantener una abstinencia alta debe darse otro ciclo de tres meses de tratamiento o mejor dicho dar un tratamiento de seis meses. La abstinencia al año con la vareniclina, después de un tratamiento de tres meses, es ligeramente superior al $20 \%$ y en el estudio de Gonzales et al. [7], dicha diferencia no fue significativa frente al bupropión. En el estudio de Tonstad et al. [9], la abstinencia al año era superior al $40 \%$, pero la abstinencia con placebo era de $37 \%$, por lo que la diferencia neta entre los dos tratamientos era marginalmente significativa $6,7 \%$. Aún con tratamiento de vareniclina de seis meses de duración, a los seis meses sin tratamiento los abstinentes con respecto al placebo son un grupo muy pequeño. Tanto en el estudio de Gonzales como en el de Joremby $[7,8]$, con tres meses aclaramientos menores a $30 \mathrm{ml} / \mathrm{min}$, la dosis no debe superar $0,5 \mathrm{mg} / \mathrm{bid} \mathrm{y}$ algunas veces será suficiente $0,5 \mathrm{mg} /$ día [4].

Recuerde que la nicotina es un inductor enzimático, y que al suspenderla su efecto inductor se reduce por lo que hay que tener cuidado con fumadores usando medicamentos como: warfarina, teofilina, insulina y anticonceptivos orales. $[5,6]$.

de terapia, la diferencia de la abstinencia al año, comparada con placebo, era como de $13 \%$, es decir, casi el doble de la que se encuentra al tratar a los pacientes con seis meses de vareniclina, según nos muestra el estudio de Tonstad [9]. Después de seis meses de terapia, en el mejor de los casos, los abstinentes al año no son más que los abstinentes después de tratamientos de tres meses de duración, si lo comparamos con el placebo. Los pacientes son abstinentes mientras tomen la medicación y como sucede en casi todo tipo de terapia para la adicción a la nicotina, después de un año solo un porcentaje muy pequeño continúa en abstinencia. El médico debe tomar en cuenta que los porcentajes de abstinentes son de estudios clínicos con seguimiento, apoyo, control con entrevistas personales y llamadas por teléfono. En la consulta diaria cuando lo que se hace es prescribir el medicamento y dar algún consejo, estos porcentajes de abstinencia deberán ser aún menores. 


\section{Semanas de abstinencia de fumado según tratamiento}

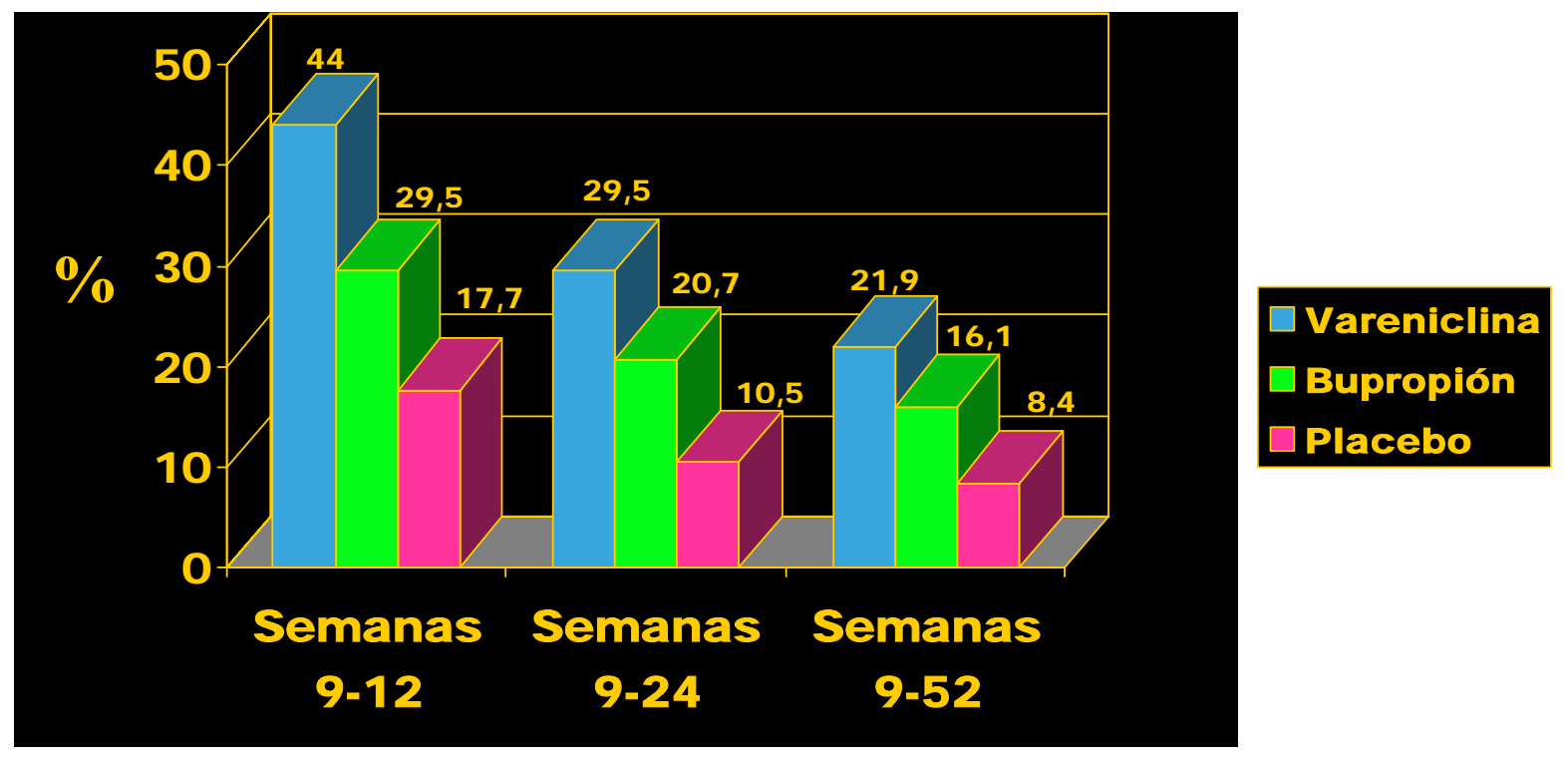

Gráfico \# 1. Datos tomados de referencia \# 7. Semanas 9-52 Vareniclina vs Bupropión diferencia no significativa. Promedio de cigarrillos fumados por día, en el mes anterior al estudio, en todos los grupos de tratamiento fue de 21 . El promedio de años de fumado fue de 24 años.

Algo interesante, aún por estudiar más detalladamente, con este fármaco es si será útil para tratar los adictos al alcohol y la nicotina o los adictos solo al alcohol [10].

El Instituto Nacional de Salud y Excelencia Clínica (NICE), por sus

\section{Efectos adversos [5]:}

Parece ser que lo más frecuente son náuseas que se presentan hasta en un 30\%.

Otros: estreñimiento, gases y vómito [4]. siglas en inglés, a publicado una guía con respecto a la vareniclina [11]. En ellas afirma que los estudios clínicos demuestran que al vareniclina es más eficaz que el bupropión y la terapia de sustitución con nicotina para mantener la abstinencia.

Insomnio (despertar temprano) 18\%.

Cefalea 15\%.

Sueños anormales 13\%.

Revista electrónica publicada por la Escuela de Medicina de la Universidad de Costa Rica, 


\section{Semanas de abstinencia de fumado según tratamiento}
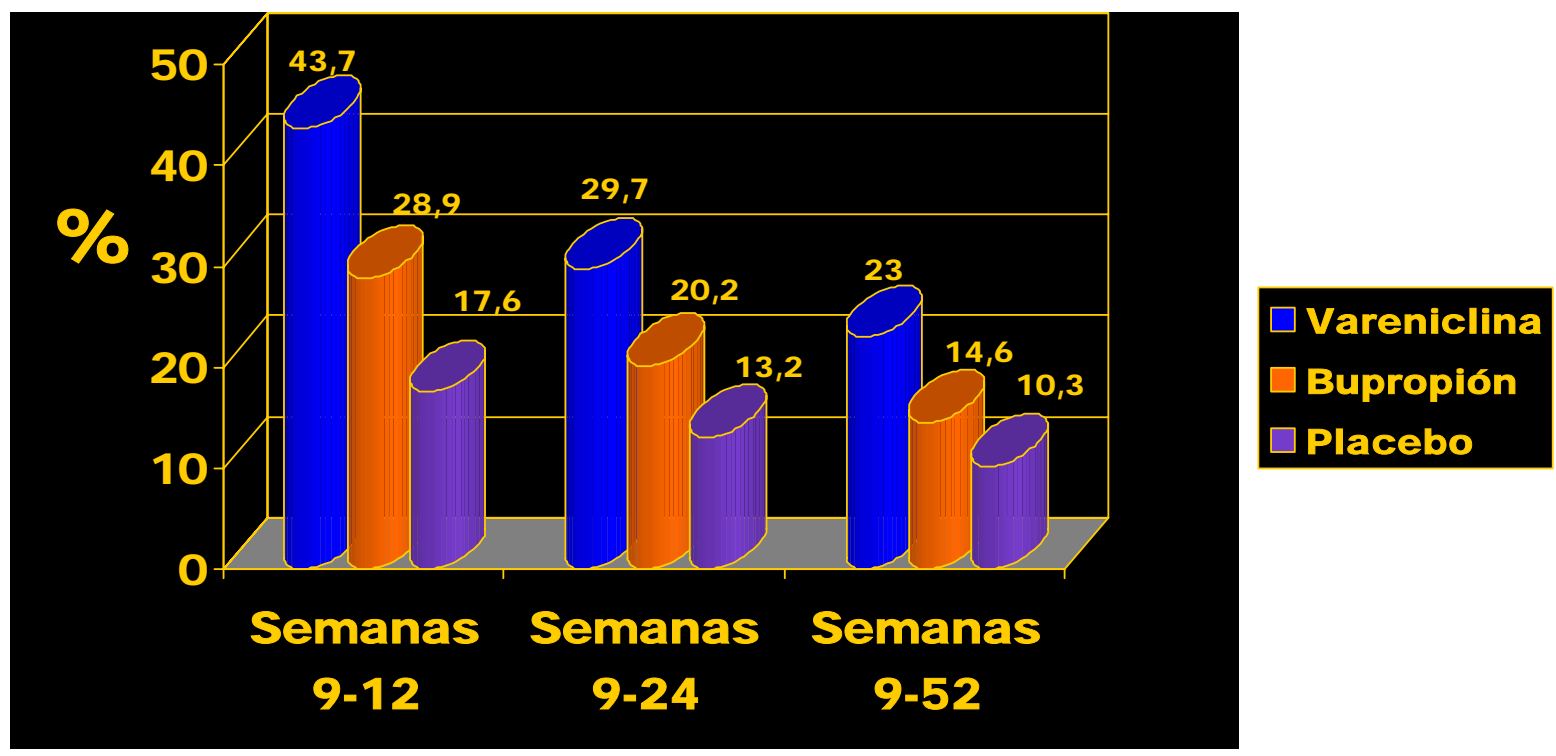

Gráfico \# 2. Datos tomados de referencia \# 8.

Preguntas sin contestar: (12)

1-¿Se mejora la eficacia al combinar vareniclina con bupropión?

2-¿Anula la vareniclina el efecto de la terapia de sustitución con nicotina?

\section{Conclusión}

Si bien la vareniclina es mejor que el placebo y parece mejor que el bupropión, la abstinencia a largo plazo sigue siendo el gran problema y la vareniclina no lo resuelve. Es un tratamiento más para este gran problema de salud pública y por eso es bien venido, pero el problema de fondo persiste, por lo que no debe ser
3-¿Mostrará la farmacovigilancia pos mercado efectos adversos serios?

4-¿Más personas dejaran de fumar definitivamente con el uso de vareniclina que con el bupropión o la nicotina de reemplazo?

considerado como una panacea, sino como un arma más. Se debe tener mucha precaución de no fundamentar todas las esperanzas y los esfuerzos de los pacientes, para dejar de fumar, a la sola adquisición de la terapia, pues esta claro que ellas no resuelven el problema. 


\section{Semanas de abstinencia de fumado en terapia de continuación de tres meses}

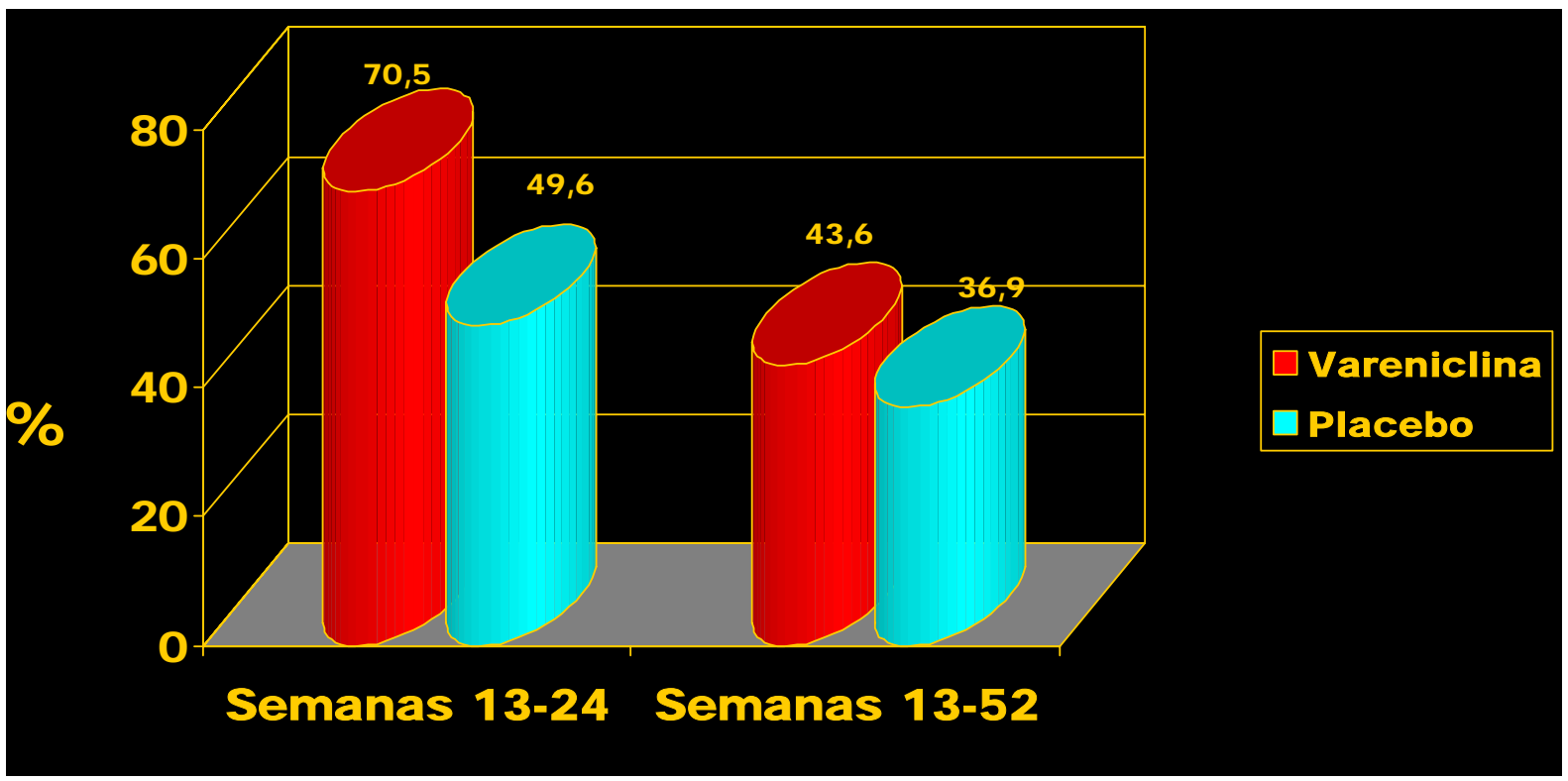

Gráfico \# 3. Datos tomados de referencia \# 9. Diferencia marginalmente significativa entre semanas 13 y 52. Pacientes ya habían sido tratados por tres meses con vareniclina y dejaron de fumar, estos que dejaron de fumar ingresaron al estudio.

\section{Bibliografía:}

1. www.fda.gov/bbs/topics/NEWS/2006/ NEW01370.html. Revisado el 26 julio del 2007.

2.www.fda.gov/fdac/features/2006/406 smoking.html. Revisado el 26 de julio del 2007.

3. http://www.fda.gov/cder/foi/label/2006 /021928lbl.pdf. Revisado el 26 julio del 2007.

4.www.pfizer.com/pfizer/download/ ppi _chantix.pdf. Revisado el 26 julio del 2007.

5. Zierler-Brown Seena y Kyle A. Jeffrey. Oral Varenicline for Smoling Cessation. Annals Pharmacotherapy enero 2007;41:95-99.
6. www.fda.gov/cder/drug/InfoSheets /patient/ChantixPIS.pdf. Revisado el 26 julio del 2007.

7. Gonzales D., et al. Varenicline, an alpha4beta2 nicotic acetylcholine receptor partial agonist, vs placebo or sustained-release Bupropión for smoking cessation. JAMA. Julio 5 2006; 296(1):47-55.

8. Jorenby D., et alt Efficacy of varenicline, an alpha4beta2 nicotinic acetylcholine receptor partial agonist, vs placebo or sustained-release Bupropión for smoking cessation. JAMA. Julio 5 2006; 296(1):56-63.

Revista electrónica publicada por la Escuela de Medicina de la Universidad de Costa Rica, 2060 San José, Costa Rica. ® All rights reserved. 
9. Tonstad Serena et al. Effect of maintenance with varenicline on smoking cessation: a randomized controlled trial. JAMA. Julio 5 2006;296(1):64-71.

10. Leeman Robert, Huffman Christoher y O'Malley Stephanie. Alcohol history ar 8 smoking cessation in nicotine replaceme theraphy, Bupropión sustained release ar varenicline trials: a review. Alcohol \& Alcoholism 2007;42(3):196-206.

11. NICE technology appraisal guidance 123. Varenicline for smoking cessation. Julio 2007.

12. Schroeder Steven. Trials that matter: varenicline: a disegner drug to help smokers quit. Annals Internal Medicine. Noviembre 21 2006;145(10):784-785.

\section{Correspondencia:}

Ronald González Argüello

Departamento Farmacología UCR.

rrgonzal@cariari.ucr.ac.cr 